Background Bereaved people need to tell their story. Often they are bursting to do so. Yet families can't always listen; churches are often locked; bereavement and counselling services have waiting lists and GPs lack time to listen. This project seeks to give bereaved people a chance to tell their story. Hospice volunteers are based in a local healthcare centre (Beacon Medical Group, Plymouth). The project is inspired by the Community Chaplaincy Listening project (Scotland).

Aims The main aim is to offer bereaved people the opportunity to tell their story thus offering a social, cathartic or therapeutic experience. A subsequent aim is for St Luke's Hospice Plymouth to widen its reach. Hospice care is reaching out to people whose loved one was not known to the hospice; the death may have been accidental, suicidal or homicidal.

Methods GPs identify people for whom bereavement is an issue and introduce the service. The person self-refers via a brief form. The coordinator books people in to see trained listeners who are available on a set day per week offering four sessions each 1.5 hours long. The listener explains that the bereaved person decides how often they want to be seen and that just attending once may be helpful. The person is sent a feedback questionnaire.

Results Out of 12 potential referrers (GPs) three referred in the first month. Seven out of 12 sessions were utilised by six women and one man; one other didn't attend. Three lost their parent; four lost their spouse. All attended once and are aware they can return. One questionnaire has been returned evaluating the service as excellent across 10 domains.

Conclusion The pilot will be evaluated fully in October 2017.

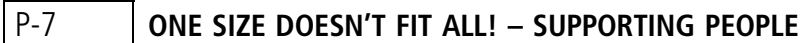 THROUGH BEREAVEMENT}

Jane Murray, Suzanne McCarthur, Ann Scanlon, Sarah Wells. Marie Curie Hospice West Midlands, Solihull, UK

\subsection{6/bmjspcare-2017-hospice.34}

Background Grief is a normal response following a loss and not all people who are bereaved will need support or counselling [Graves, 2009]. Bereaved people approach their grief in a variety of different ways. Terry Martin and Kenneth Doka recognised that there are different patterns to grieving, these might or might not be related to male or female gender characteristics, and be more about coping strategies that a person develops. The traditional way of formally supporting people who have been bereaved is telephone support or face-to-face/ one to-one counselling. Many people who are bereaved who consider support choose not to access these traditional services due to their own individual way of grieving; different coping strategies, and limited alternative support services available.

Results In response to the literature and requests from bereaved family members, Marie Curie Hospice, West Midlands has developed a broader range of bereavement support services that has scope to encompass individual ways of grieving. These include the traditional one-to-one support; family support sessions and remembrance services. In addition the Hospice Bereavement Support service also offers a hospice choir; a Walk and Talk group; a Men's Shed group, a Bereaved Social Group and a Children's Therapeutic Group. The broader range of support provides greater choice where people who have been bereaved can come together regardless of what point on the bereavement pathway they are on and meet others who are going through a similar life event. The uptake of the new services has been positive, with activity continually increasing. More men are now accessing bereavement support services and with the on-going development of a volunteer team, we are now able to offer children the opportunity to meet together and share their own experiences in a safe environment.

\section{P-8 DIGITAL COMMUNICATION AND SUPPORT- ONLINE BEREAVEMENT SUPPORT GROUP}

Lynsey Lawson. St Mary's Hospice, Ulverston, UK

\subsection{6/bmjspcare-2017-hospice.35}

Background Responding to emerging need. Whatever stage of the bereavement process you are in, you can always seek online support. Many choose this style of therapy because grieving about their loved ones happens from the privacy of their own homes. One post on Facebook or Twitter can take the place of fifty or more conversations. You may have dreaded the thought of telling people over and over again about a death or how you are coping and social media gives you the opportunity to tell people all at once. Why say it yourself when you can tweet a beautiful quote that says it for you? Our aim is to develop an online support group, which will be run by trained bereavement volunteers. The Group aims will be to provide:

- A chance for people to share their grief with other bereaved members.

- A place for people to talk about their loved ones without feeling unwelcome or uncomfortable.

- A safe place to post poetry, photographs, journals or articles about their loved one who has died.

- An opportunity for people to meet locals who can offer support, many times people who meet online and live in the same area often get together.

- A chance for people to feel less lonely in their grief.

- A place for people to learn coping skills, stress management techniques and ways to relax.

- Advice and information following bereavement.

Methods During initial assessment for bereavement support patients will be provided with a 'Online Bereavement Group' leaflet which will provide details including. How do I join the group? How might the group offer support? And Confidentiality and record keeping. Once a member of the group, patients will be supported by other online members and bereavement volunteers.

\section{P-9 COMMUNICATING LOSS - A NEW APPROACH TO BREAKING BAD NEWS TO PATIENTS WITHIN A HOSPICE DAY UNIT}

Sarah Holl, Jenny Hadley, Katherine Birch. Compton Hospice, Wolverhampton, UK

\subsection{6/bmjspcare-2017-hospice.36}

Background Within our day unit, patients develop friendships with one another and telling them about the death of a former patient can be difficult and distressing. Up until recently, we typically told patients about the loss of a former patient on an individual basis. However, we were concerned about the way this was delivered and the impact this had on the individual and the group as a whole. 